\title{
Critical Care of the Solid Organ Transplant Patient Part I: Heart and Lung Part II: Liver, Kidney, and Small Bowel
}

\section{Editors}

KENNETH R. MCCURRY

ALI AL-KHAFAJI

\section{CRITICAL CARE CLINICS}

www.criticalcare.theclinics.com

Consulting Editor

JOHN A. KELLUM

January 2019 • Volume 35 • Number 1 